\title{
MARTENSITIC TRANSFORMATION AND METALLURGICAL STUDY OF LOW TEMPERATURE CU-Al- Be TERNARY ALLOY
}

\author{
S. BELKAHLA ${ }^{(1)}$ and G. GUENIN \\ Institut National des Sciences Appliquées de Lyon, Groupe d'Etudes de Métallurgie Physique et de \\ Physique des Matériaux, ERA CNRS $N^{\circ}$ 341, Bât 502, 20 Ave. A. Einstein, F-69621 Villeurbanne, \\ France
}

\begin{abstract}
The present study on a Cu-Al-Be alloy has given the following characteristics: the addition of small concentration of beryllium to the eutectoïdal alloy close to $\mathrm{Cu}_{3} \mathrm{Al}$ leads to a sharp decrease of the martensitic transformation temperatures. At the same time the composition corresponding to the maximum stability of the beta phase does not change significantly. The eutectoildal temperature is lowered, but the temperature of beta solution treatment remains the same. Moreover there is no change in the nature of the martensitic transformation ( $\left.\mathrm{DO}_{3} \leftrightarrow 18 \mathrm{R}\right)$. All these properties are very interesting from the industrial point of view: whatever is the $M_{S}$ temperature chosen, the beta phase stability will be approximately the same since the alloy is always close to the "eutectoildal" composition. This alloy will be the complement of $\mathrm{Cu}-\mathrm{Al}-\mathrm{Ni}$ alloy towards low transformation temperatures (from $-200^{\circ} \mathrm{C}$ to $+60^{\circ} \mathrm{C}$ ) with approximately the same stability at high temperature.
\end{abstract}

\section{INTRODUCTION}

Many investigations for application uses have been reported on $\mathrm{Cu}$-base shape memory alloys such as $\mathrm{Cu}-\mathrm{Zn}-\mathrm{Al}, \mathrm{Cu}-\mathrm{Al}-\mathrm{Ni}$, etc..., but the first one is very sensitive to aging (1-2) and martensitic stabilization (3) and therefore cannot be used above $100^{\circ} \mathrm{C}$, and the second alloy becomes fragil when its martensitic transformation temperature domain is below about $50^{\circ} \mathrm{C}$; moreover this martensitic transformation changes from $\beta_{1} \rightarrow 18 \mathrm{R}$ to $\beta_{1} \rightarrow 2 \mathrm{H}$ and becomes less reversible (4). A gap is therefore present corresponding to alloys transforming below $50^{\circ} \mathrm{C}$ and resisting to aging at about $200^{\circ} \mathrm{C}$. Fragmentary results on $\mathrm{Cu}-\mathrm{Al}-\mathrm{Be}$ alloy (5-7) allow to hope that this alloy can fill this gap. The purpose of this work is to explore this alloy from metallurgical point of view (phase diagram) and martensitic transformation (control of transformation temperature).

\section{EXPERIMENTAL}

The alloys are prepared by induction melting of $\mathrm{Cu}-4 \%$ Be commercial alloy, pure aluminium $(99,99 \%)$ and electrolytic copper, into an evacuated chamber under a nitrogen rich atmosphere. Cylindrical ingots are obtained by in-situ pouring of the

(1) On leave of absence from University of Annaba, Institut of Physics, BP. 12, Annaba, Algérie. 
liquid alloy into bulk copper molds. The polycrystals are then homogenized at $850^{\circ} \mathrm{C}$ for 5 hours and quenched into water at room temperature. Chips are collected for analyse by Plasma Emission Spectroscopy and the resulting compositions are obtained with $0,02 \%$ accuracy.

Samples of $100-150 \mathrm{mg}$ are cut out from the ingots for the measurements of Differential Scanning Calorimetry (DSC). Conventionally the $\mathrm{M}_{\mathbf{s}}$ temperature is chosen for $10 \%$ of martensite transformation and DSC curves are measured at a rate of $5^{\circ} \mathrm{C} / \mathrm{min}$ (unless otherwise stated). Samples of size $\left(4 \times 4 \times 40 \mathrm{~mm}^{3}\right)$ are cut for dilatometry measurements. Dilatometry and DSC curves which allow to determine the variations of the eutectoïdal temperature are made at a rate of $0,5{ }^{\circ} \mathrm{C} / \mathrm{mn}$.

\section{RESULTS and DISCUSSION}

The compositions and eutectoïdal temperatures for fifteen alloys used to determine the beryllium content influence on the eutectoïdal temperature are given in table 1 . For these alloys the transformation cycles are accomplished from 0 to $600{ }^{\circ} \mathrm{C}$ at a rate of $0.5^{\circ} \mathrm{C} / \mathrm{min}$. The eutectoildal temperature as a fonction of beryllium content is displayed on figure 1 .

Figure 1a shows that the eutectoïdal temperature first decrease until about 0.7 wt\% beryllium then increases to be stable above $1 \%$ Be. Figure $1 \mathrm{~b}$ exhibits the same evolution focussed on beryllium percentages used in the following. Indeed alloys with more than $0.7 \mathrm{wt} \%$ beryllium have an $\mathrm{M}_{\mathrm{s}}$ temperature below $-210^{\circ} \mathrm{C}$ as will be seen later and are not industrially very useful. In the studied domain a linear decrease of the eutectoïdal temperature with beryllium content is observed. The eutectoïdal temperature, considered here, is the average value between eutectoildal temperature obtained at increasing temperature and the one determined at decreasing temperature. The DSC apparatus being limited to $600^{\circ} \mathrm{C}$, dilatometry measurements have been used to bring more informations on the phase diagram at higher temperatures (up to $900^{\circ} \mathrm{C}$ ). Concerning the eutectoïdal temperature the two experimental techniques are in good agreement.

The results obtained by these measurements (calorimetry, dilatometry) on alloys of tables 1 and 2 allow to draw a section of the Cu-Al-Be ternary diagram for $0.47 \mathrm{wt} \%$ beryllium (see figure 2). It can be stated that the minimum temperature of $\beta$ phase stability $\left(600^{\circ} \mathrm{C}\right)$ is close to $11.8 \mathrm{wt} \%$ aluminium composition, that is to say at almost the same place than for the binary $\mathrm{Cu}-\mathrm{Al}$ alloy. Moreover the eutectoiddal temperature exhibits a decrease of $50^{\circ} \mathrm{C}$ in relation to the one of the binary alloy. A new ternary domain $\left(\alpha+\beta+\gamma_{2}\right)$ occurs for this composition domain between the minimum temperature of $\beta$ phase stability and the eutectoïdal temperature.

Table 2 gives the compositions and $\mathrm{M}_{\mathrm{s}}$ temperatures for eight alloys elabored with constant beryllium content in order to determine aluminium influence on transformation temperatures. The linear variation of $\mathbf{M}_{\mathbf{S}}$ temperature with aluminium content (see figure $3 \mathrm{a}$ ) allows to deduce an influence coefficient of $71 \pm 8^{\circ} \mathrm{C}$ by weight percent for aluminium.

Table 3 gives the compositions and $M_{S}$ temperatures for twenty-one alloys elabored with aluminium content close to the "eutectoidal" composition. The linear variation of $\mathrm{M}_{\mathrm{s}}$ transformation temperature with beryllium content (see figure $3 \mathrm{~b}$ ) allows to determine an influence coefficient of $893 \pm 20^{\circ} \mathrm{C}$ by weight percent for beryllium. 
From these results, the following relation can be written which is valid for aluminium and beryllium contents included between 10-12,5\% and 0,3-0,65\% respectively:

$$
\mathrm{M}_{\mathrm{S}}\left({ }^{\circ} \mathrm{C}\right)=1245-71 \% \mathrm{Al}-893 \% \mathrm{Be}
$$

The first striking feature that can be deduced is the very high sensitivity of the transformation temperature to the alloy composition especially for beryllium.

Figure 4 shows typical DSC curves at cooling for a specimen of alloy (CAB 5) aged at 220 and $260^{\circ} \mathrm{C}$ for various times. As can be seen from the curves the martensitic transformation is not appreciably affected by $220^{\circ} \mathrm{C}$ or $260^{\circ} \mathrm{C}$ aging as long $100 \mathrm{~h}$. A small shift toward high temperatures is noticed above $200 \mathrm{~h}$ aging. whereas some degradation of the shape of the DSC curve is observed correlated with an increase of the hysteresis of the transformation. The degradation is probably due to the partial decomposition of the $\beta_{1}$ phase into products close to $\alpha$ and $\gamma_{2}$ which acts on the transformation temperatures (modification of the remaining $\beta 1$ phase) and the hysteresis (obstacles to interfaces movements).

\section{CONCLUSION}

From the present study the following conclusions can be given:

- An addition of small concentrations of Beryllium to $\mathrm{Cu}$-Al alloys close to the eutectoïdal composition leads to a sharp decrease of the martensitic transformation temperatures.

- The aluminium composition corresponding to the maximum stability of the $\beta$ phase does not change significantly.

- The eutectoïdal temperature is lowered, but the temperature of $\beta$ solution treatment remains the same.

From other measurements not shown here it has been proved that the nature of the martensitic transformation is not affected ( $\mathrm{DO}_{3} \leftrightarrow 18 \mathrm{R}$ ). All these properties are interesting: whatever is the $\mathrm{M}_{\mathbf{s}}$ temperature chosen (between $-200^{\circ} \mathrm{C}$ and $50{ }^{\circ} \mathrm{C}$ ) by addition of $\mathrm{Be}$ to the eutectoïdal $\mathrm{Cu}-\mathrm{Al}$ alloy, the $\beta$ phase stability will be approximately the same since the alloy stays always close to the eutectoildal composition. This alloy is therefore the good complement of $\mathrm{Cu}-\mathrm{Al}-\mathrm{Ni}$ alloy towards low transformation temperatures with approximately the same resistance to ageing.

Acknowledgements: S. Belkahla has been supported by Tréfimétaux for this work.

\section{References}

(1) Contardo L., Doctoral thesis, INSA-Lyon, (1988), 118 p., France.

(2) Belkahla S., Magister thesis, Université de Annaba, (1985), 87 p., Algérie

(3) Mantel M., Doctoral thesis, INSA-Lyon, (1985), 144 p., France.

(4) Rodriguez P., Doctoral thesis, INSA-Lyon, (1989), 197 p., France.

(5) Higuchi A., Suzuki K., Matsumoto Y., Sugimoto K., Komatsu S. and Nakamura Y., Journal de Physique, C4, T. 43, (1982), 767.

(6) Higuchi A., Suzuki K., Sugimoto K., and Nakamura Y., ICOMAT (1986), 886, Japan.

(7) Goodwin R.J. and Stephens D.M., Report N Gr/R/14.to INCRA (1967), USA. 


\begin{tabular}{|c|c|c|c|}
\hline Référence & $\begin{array}{c}\% \mathrm{Al} \\
(\mathrm{wt})\end{array}$ & $\begin{array}{c}\% \mathrm{Be} \\
(\mathrm{wt})\end{array}$ & $\begin{array}{c}\text { T. eut. } \\
\left({ }^{\circ} \mathrm{C}\right)\end{array}$ \\
\hline CAB 94 & 11,53 & 0 & 558 \\
\hline CAB 3 & 11,42 & 0,31 & 520 \\
\hline CAB 12 & 11,67 & 0,33 & 513 \\
\hline CAB 10 & 11,57 & 0,37 & 512 \\
\hline CAB 15 & 11,66 & 0,42 & 511 \\
\hline CAB 4 & 11,50 & 0,43 & 510 \\
\hline CAB 14 & 11,79 & 0,47 & 509 \\
\hline CAB 64 & 11,91 & 0,47 & 508 \\
\hline CAB 19 & 11,67 & 0,51 & 508 \\
\hline CAB 13 & 11,72 & 0,52 & 508 \\
\hline CAB 17 & 11,79 & 0,54 & 508 \\
\hline CAB 2 & 11,40 & 0,65 & 505 \\
\hline CAB 90 & 11,74 & 0,95 & 515 \\
\hline CAB 91 & 11,73 & 1,42 & 517 \\
\hline CAB 92 & 11,79 & 1,90 & 517 \\
\hline
\end{tabular}

Table 1: Beryllium content influence on eutectoïdal temperature.

\begin{tabular}{|c|c|c|c|}
\hline Référence & $\begin{array}{c}\% \mathrm{Al} \\
(w t)\end{array}$ & $\begin{array}{c}\% \mathrm{Be} \\
(w t)\end{array}$ & $\mathrm{M}_{\mathbf{s}}\left({ }^{\circ} \mathrm{C}\right)$ \\
\hline CAB 52 & 10,37 & 0,47 & 95 \\
\hline CAB 53 & 10,88 & 0,47 & 50 \\
\hline CAB 54 & 11,35 & 0,47 & 13 \\
\hline CAB 55 & 11,65 & 0,47 & -6 \\
\hline CAB 56* & 11,65 & 0,47 & 0 \\
\hline CAB 57 & 12,27 & 0,47 & -36 \\
\hline CAB 64 & 11,91 & 0,47 & -25 \\
\hline CAB 60 & 12,45 & 0,47 & -61 \\
\hline
\end{tabular}

\begin{tabular}{|c|c|c|c|}
\hline $\begin{array}{l}\text { Référence } \\
\text { CAB 3 }\end{array}$ & $\begin{array}{c}\% \mathrm{Al} \\
(\mathrm{wt})\end{array}$ & $\begin{array}{c}\% \mathrm{Be} \\
(\mathrm{wt})\end{array}$ & $\mathrm{M}_{\mathbf{s}}\left({ }^{\circ} \mathrm{C}\right)$ \\
\hline CAB 12 & $11,4_{2}$ & 0,31 & 159 \\
\hline CAB 10 & $11,5_{7}$ & 0,33 & 121 \\
\hline CAB 15 & $11,6_{6}$ & 0,42 & 43 \\
\hline CAB 4 & $11,5_{0}$ & 0,43 & 42 \\
\hline CAB 6 & $11,4_{5}$ & 0,47 & 1 \\
\hline CAB 14 & 11,79 & 0,47 & -10 \\
\hline CAB 18 & 11,76 & 0,47 & -7 \\
\hline CAB 24 & $12,0_{4}$ & 0,47 & -20 \\
\hline CAB 19 & 11,67 & 0,51 & -48 \\
\hline CAB 23 & $12,0_{4}$ & 0,51 & -55 \\
\hline CAB 13 & $11,7_{2}$ & 0,52 & -41 \\
\hline CAB 7 & $11,4_{1}$ & 0,52 & -34 \\
\hline CAB 56 & 11,63 & 0,52 & -47 \\
\hline CAB 5 & 11,65 & 0,52 & -50 \\
\hline CAB 22 & 11,69 & 0,54 & -64 \\
\hline CAB 17 & $11,7_{9}$ & 0,54 & -64 \\
\hline CAB 8 & $11,4_{6}$ & 0,55 & -70 \\
\hline CAB 21 & $11,7_{0}$ & 0,56 & -84 \\
\hline CAB 20 & $11,7_{8}$ & 0,57 & -95 \\
\hline CAB 2 & $11,4_{0}$ & 0,65 & -147 \\
\hline
\end{tabular}

Table 3: Beryllium content influence on $\mathrm{M}_{\mathrm{s}}$ temprature.

Table 2: Aluminium content influence on transformation temperature (* single crystal). 


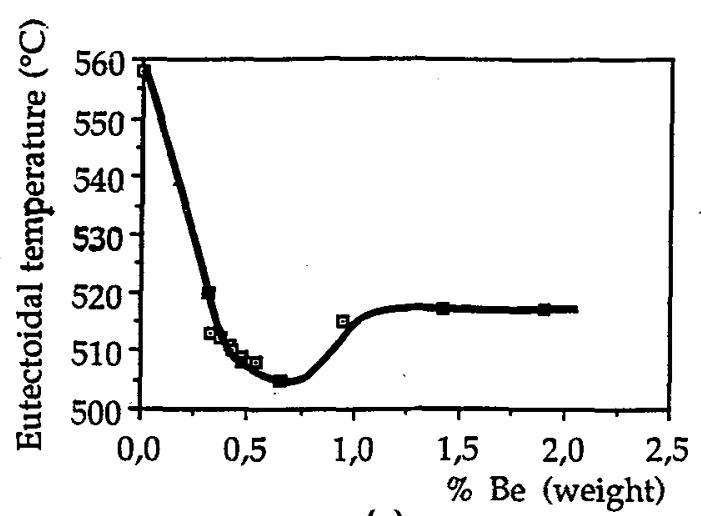

(a)

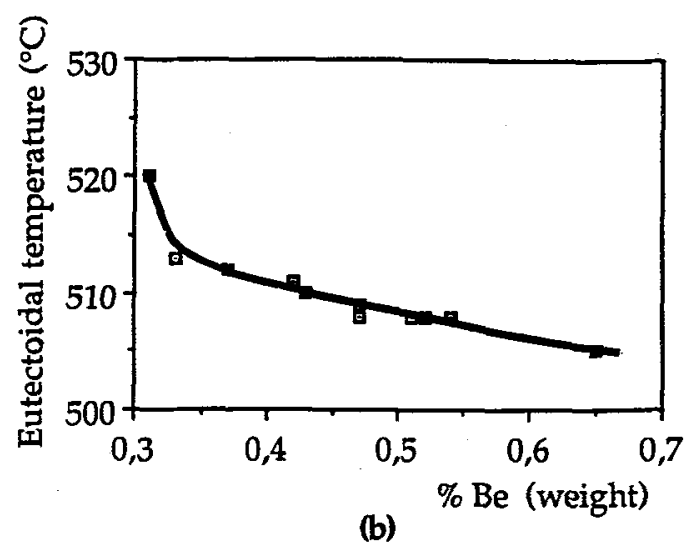

(b)

Figure 1: Beryllium content influence on eutectoïdal temperature.

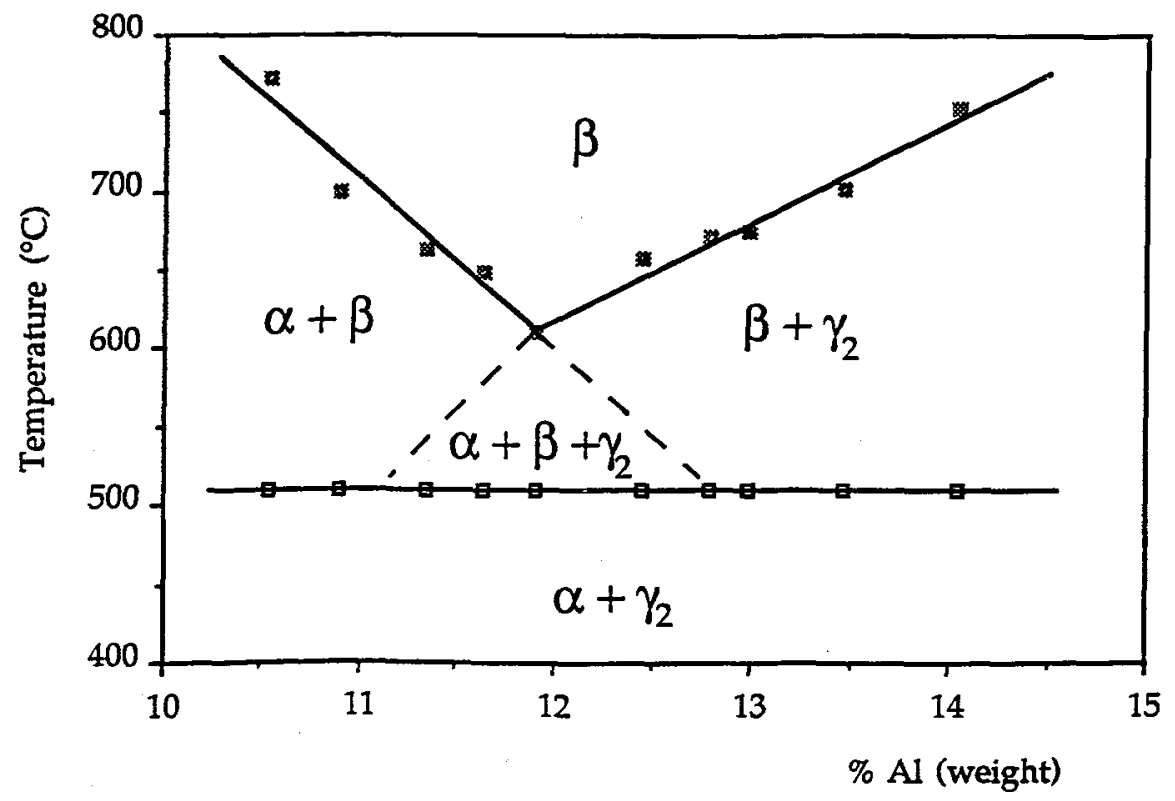

Figure 2: Section at $0.47 \% \mathrm{Be}$ of $\mathrm{Cu}-\mathrm{Al}-\mathrm{Be}$ ternary alloy. 


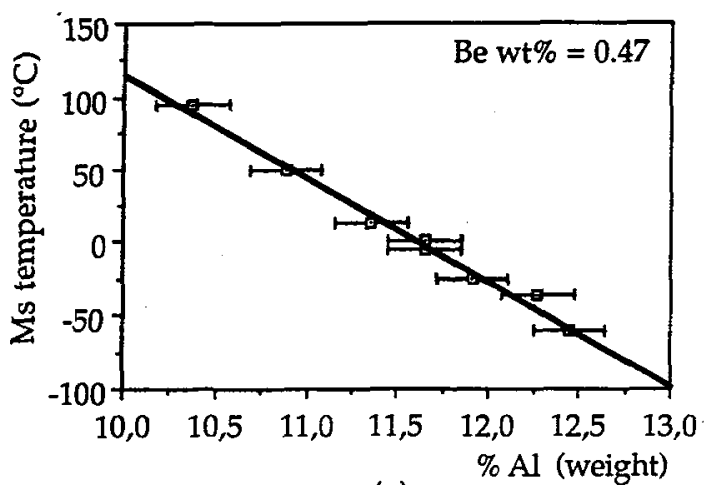

(a)

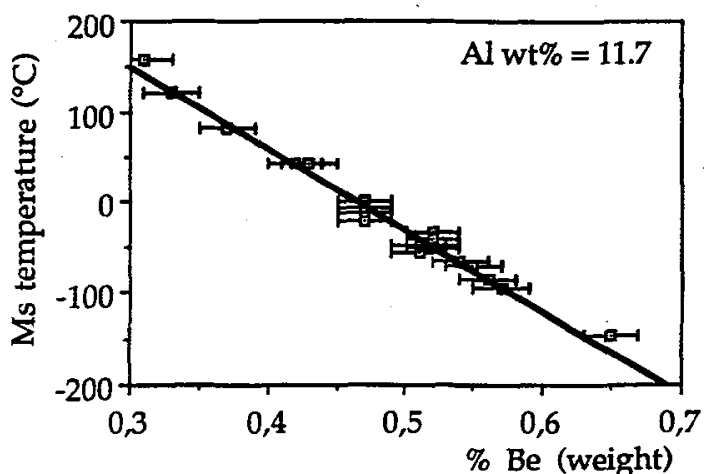

(b)

Figure 3: Correlation between aluminium (a) and beryllium (b) contents and $\mathrm{M}_{\mathrm{S}}$ transformation temperatures in $\mathrm{Cu}-\mathrm{Al}-\mathrm{Be}$ ternary alloy.
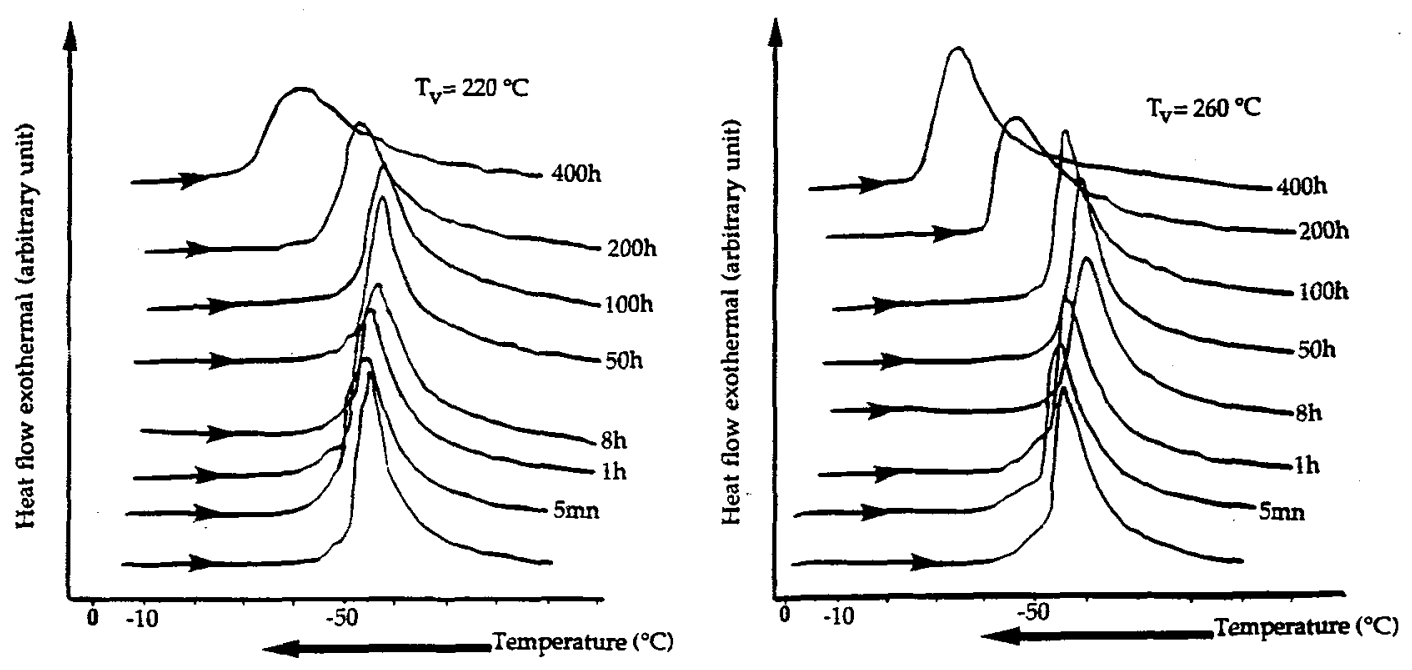

Figure 4: DSC curves after aging at 220 and $260^{\circ} \mathrm{C}$ for various times in alloy CAB 5 on cooling. 